\title{
CARENCIAS, LIMITACIONES, FRUSTRACIONES Y ESPERANZAS DE LA VIDA MILITANTE DE LA IZQUIERDA COSTARRICENSE EN LOS AÑOS SETENTA Y OCHENTA ${ }^{1}$
}

\author{
Roberto Salom E.
}

Ignacio Dobles Oropeza y Vilma Leandro Zúñiga. "Militantes" La vivencia de lo político en la segunda ola del marxismo en Costa Rica. San José, CR. Editorial Universidad de Costa Rica. 2005.

El trabajo, como su título lo sugiere, trata de una reflexión sobre la experiencia política en la izquierda costarricense de los años setenta $y$ ochenta a partir de 40 entrevistas a hombres $y$ mujeres, en su gran mayoría militantes de base de esos partidos u organizaciones políticas.

El propósito enunciado por Ignacio Dobles y Vilma Leandro consiste en "rescatar" la historia reciente de nuestro país (o una parte de ella), "a través de las voces de sus protagonistas"; además, para ubicar el perfil ideológico-político de estos y de las organizaciones a las que pertenecieron, se propusieron "trabajar la "historia" de quienes se ubicaron en el lugar de intentar llevar a cabo transformaciones radicales de la estructura socio-económica en beneficio de las mayorías" (p.376).

No se trata, sin embargo, de rescatar la historia por la historia misma, "el 'rescate' se lleva a cabo en función de un presente, de una autovaloración y en el mejor de los casos, en función de

1 La presente reseña se preparó para la presentación $y$ los comentarios a esta obra en el acto oficial celebrado el 18 de octubre de 2006, en el miniauditorio de la Facultad de Ciencias Sociales de la Universidad de Costa Rica. un proyecto compartido", dicen quienes realizan la investigación (p.377). Es decir, que hay aquí un compromiso con el propósito, no se trata tan solo de una investigación académica o de un ejercicio puramente intelectual.

Igualmente, —dicen — "se intenta... articular lo político con lo subjetivo bajo el supuesto de que la política no es una categoría abstracta, sino que son personas las que concretizan estas prácticas y los intentos de promover objetivos e intereses grupales" (p.377).

El estudio se realiza con una metodología cualitativa en la que no tiene sentido procurar algún nivel de representatividad de las opiniones; una opinión puede resultar tan significativa como las demás; en otras palabras, en la indagación, no necesariamente todas las entrevistas tienen el mismo valor. El dato cuantitativo en este caso, no es relevante; no se puede hablar de muestra propiamente, de manera que el total de los entrevistados y las entrevistadas constituye el total de la población.

¿Cómo obtener o sacar conclusiones a partir de la información que brindan las entrevistas? Se trata, en cierto modo de destacar lo que se decanta a lo largo del proceso investigativo,

\footnotetext{
* Escuela de Sociología y Maestría en Sociología de la Facultad de Ciencias Sociales, Universidad de Costa Rica.rrsalom@ice.co.cr
} 
independientemente inclusive, de la veracidad, exactitud o precisión de las formulaciones de las personas entrevistadas, puesto que se trata de valorar la conjugación de lo político con lo subjetivo, o como dice el texto "se intenta... articular lo político con lo subjetivo" bajo el supuesto o la premisa, si se prefiere, que la política no es una categoría abstracta, "son personas las que concretizan las prácticas” (p.377).

La multiplicidad de dimensiones implicadas hace muy complejo el análisis de la información, aparte, como ya se dijo, de la dificultad propia que las entrevistas individualizadas ofrecen para arribar a conclusiones.

En abono a este tipo de investigación, el texto trae a cuento a Portelli, quien "se ha encargado de señalar en sus investigaciones con militantes comunistas italianos, que muchas veces las 'fantasías' de viejos militantes, articuladas en torno a elementos rescatados de la memoria y la imaginación colectiva, podían ser más útiles para la comprensión de lo que había ocurrido en las versiones 'oficiales' de los dirigentes partidarios" (pp.306-307). En realidad, diría yo, tan útiles o tan problemáticas una como la otra a la luz de un análisis histórico, sociológico y político. De hecho aquí se contemplan ambos, si bien solo un miembro de dirección fue entrevistado, mientras que todas las demás entrevistas son de militantes de base de los partidos u organizaciones involucradas en el estudio.

Lo que se pretende es organizar la información de manera que permita arribar a algunas conclusiones de acuerdo con el propósito de la investigación y ya hemos visto que esta no carece de tal propósito. En ese sentido, como se dice en el estudio, "la pérdida, la fractura, el cese de la militancia o la 'muerte súbita' de proyectos políticos, tienden a ser eventos biográficos altamente relevantes" (p.307). Desde luego no es casual que se hable de pérdida, puesto que, como es sabido, se trata de un estudio de militantes de organizaciones que sufrieron esos procesos y tales organizaciones han dejado ya este mundo o han entrado en una más o menos larga agonía.

Se trata en suma de una estrategia de carácter cualitativo, mediante la cual se pretende "abordar la subjetividad de nuestros entrevistados y entrevistadas - dice el texto- y resaltar núcleos problemáticos percibidos en los procesos vividos" (p.377).

Mediante la entrevista, que es el instrumento investigativo por excelencia, se hace una incitación a reelaborar versiones de la propia vivencia, sobre asuntos desafiantes para la militancia con la que se hizo la investigación (p.378).

Por lo anterior interesan entonces los significados y las percepciones de quienes fueron militantes de las organizaciones de izquierda durante las décadas estudiadas. Como se dice en el texto, lo que se pretendió no fue establecer "veracidades", sino sentidos (p.380), para hombres y mujeres que, como quienes integraron las organizaciones de izquierda tenían en común, más allá de las características de cada uno de estos partidos u organizaciones, la de asumir la militancia como un estilo de vida, cuya experiencia marcó profundamente en un sentido o en otro, sus existencias. No es ocioso insistir en la intensidad, profundidad e integridad del compromiso militante de la mayor parte de quienes adhirieron a estas organizaciones de izquierda, así como la radicalidad de su opción; especialmente si lo comparamos con el tipo de adhesión que suele establecerse en otras organizaciones políticas. Por ello, como lo expresan los autores, "los cambios acaecidos en el espectro político, al tratarse de proyectos de alta inversión personal y emocional, generan cismas, "dislocaciones" y cuestionamientos que en algunos casos son canalizados mediante "retornos" a la vida religiosa anterior o mediante nuevas búsquedas espirituales, que no necesariamente implican abandonar el compromiso social o político" (pp.145-146).

Más bien la investigación concluye que quienes fueron objeto de estas entrevistas revelan una búsqueda ética y una militancia integral y también una enorme diversidad en cuanto a la forma como asumieron la experiencia (p.378).

Se destaca, en consecuencia, en el material, "matices y contradicciones", pero finalmente, "la mayoría de las personas entrevistadas consideran su paso por la 'izquierda política' costarricense como una experiencia importante, incluso formadora" (p.378).

La mayor parte de los entrevistados y de las entrevistadas perteneció al PVP, al MRP o al PSC pero también se incluyeron integrantes de 
otras organizaciones; lo que se considera que permite ubicar de mejor manera la experiencia de la izquierda en los años setenta y ochenta (p.379).

Se considera haber logrado con mayor éxito, abordar las diferencias de género con la estrategia de investigación utilizada (p.379). Aquí vale la pena que nos detengamos brevemente.

El rezago de la izquierda por aquellos años, respecto del tema de género evidencia cómo en el seno de las propias organizaciones se cuela la ideología y más que eso, la cultura dominante; como se señala en el texto "el mismo medio le resultaba intimidatorio a las militantes" (p.255). No obstante, se apunta que la militancia cimentó una futura vinculación con el trabajo de género (p.257).

Pero lo cierto es que el tema de género no tenía consideración o atención política (p.257); excepto en la OST, había una negación del género como tema político, una incomprensión por parte de la izquierda de esta problemática.

Claramente hay que decir que la izquierda no auspició el desarrollo posterior de la lucha de género, ni otro tipo de luchas relacionadas con el reconocimiento de los derechos de otros grupos en la sociedad, perspectivas que emergieron después del languidecimiento de estas organizaciones.

Ni en lo social, ni en cuanto a los militantes y las militantes en particular, la izquierda estimuló una propuesta por la equidad de género, con la única excepción ya hecha; ni tampoco promovió entre la militancia la consciencia y la práctica en procura de la equidad de género. Más bien, como se reconoce en el texto, una práctica que pretendía ser liberadora, creaba "dificultades adicionales" a la mujer (p.265).

Sin embargo, como se destaca en el libro, no parece que halla consenso entre la militancia sobre esta problemática y en particular sobre la incidencia del orden social patriarcal en la dinámica de los partidos y en la reproducción de la situación de inequidad de género, así como de las relaciones de género discriminatorias características de una sociedad patriarcal. Más bien en las organizaciones, con toda la intensidad que significó la vida militante, se reprodujeron las prácticas de subordinación de la mujer propias de una sociedad machista.
En cuanto a lo emocional, se buscaba entrar en contacto con un pasado "engavetado" y lacerante (p.380). Por otra parte, perder el marco de actuación política... ha significado perder referentes, sentirse desubicado (p.380). Lo que a pesar de ello se procuró fue mantener los "núcleos éticos" y analizar cómo esto se ha intentado resolver en las vivencias de los entrevistados $y$ las entrevistadas (p.380).

La investigación pretendió trabajar con versiones de esa historia "tapada", acercándose a las vivencias en función del cambio social. El autor y la autora trabajaron en procura de la construcción de algún futuro a condición de que se pueda procesar efectivamente la historia (p.381). Aquí de nuevo resalta el compromiso de quienes condujeron la investigación con los propósitos de la misma.

En opinión de ellos, el material permite, entre otras cosas, evidenciar que, quienes fueron entrevistados o entrevistadas intentaron en buena medida, mantener sus "núcleos éticos" (p.381), lo que podríamos traducir, en el lenguaje político del periodo de estudio, como "los principios”.

Si hay posibilidad de revancha sobre la historia, - señalan - esta sería únicamente en la esperanza que se mantiene en muchas de las personas entrevistadas, a pesar de los costos personales en virtud de los fracasos colectivos (p.381).

"Todo esto implica revivir la experiencia —dicen los autores - ... repensar el objetivo político, volver la vista atrás desde una perspectiva actual y re-conocer compañeros, anécdotas, pegas, pintas, reuniones de células, marchas, huelgas, canciones, prejuicios, discusiones $y$, en fin, todo un mundo; el mundo de la militancia en un partido de izquierda - continúan- implica hablar sobre qué se ha hecho con todo eso, cómo se mira ahora el mundo, confronta lo que se está haciendo hoy respecto a lo que se hizo antes" (p.382).

Consideran que sobre lo realizado "puede ser interesante $y$ útil revisar y discutir en el difícil camino de articular propuestas de acción colectivas para incidir en estructuras sociales $y$ económicas marcadas por la desigualdad $y$ la injusticia" (p.383).

Empero, no se trata solo de comenzar de nuevo, el derrumbe de prácticamente todas las 
organizaciones de izquierda, abrupto o por languidecimiento, incluidos esfuerzos posteriores, no ocurrió por casualidad. Después de estos hechos se produjo la crisis y el derrumbe del campo socialista y ello de ninguna manera es ajeno a la problemática de tales organizaciones, puesto que central o periféricamente, todas estas organizaciones formaban parte de una misma tradición de lucha, incluidas las organizaciones trotskistas, algunas de las cuales sobreviven siempre con un bajo perfil.

A mi juicio se trata de una crisis paradigmática de una determinada concepción que devino hegemónica en la lucha por el socialismo a nivel mundial predominantemente influida por el marxismo-leninismo, o al menos por una o varias versiones de este pensamiento. A mi juicio, lo que ha fracasado no fue el socialismo como concepción o aun más como aspiración por un mundo mejor, lo que ha evidenciado ser una concepción y una práctica infructuosa ha sido una forma particular de lucha y de construcción del socialismo.

Si así fuera, si se trata de una crisis paradigmática como creo, la tarea para quienes creemos en el socialismo como utopía y en la necesidad de luchar integralmente contra el capitalismo, como sistema socio-económico y como cultura, rebasa con mucho la realización de una mera propuesta; comporta un esfuerzo sistemático de revisión paradigmática de lo que ha sido el pensamiento y la práctica socialista predominante, desde el triunfo de la revolución de octubre (y aún antes), hasta la caída del campo socialista ( $y$ aún después).

Esta propuesta no es nueva, ni es original, mas no por eso deja de ser una convicción profunda. Ya lo dice Ludolfo Paramio "aunque pueda parecer un juicio demasiado tajante, cabe afirmar que el programa marxista-leninista entra en una fase de regresión incluso antes de la muerte de Lenin. El curso posterior, con las sucesivas hipótesis de construcción del socialismo en un solo país, y de coexistencia/competencia entre un mundo capitalista $y$ un mundo socialista, no solo no aporta ninguna nueva capacidad explicativa, sino que entra en contradicción de forma explícita con las premisas de la teoría: que el capitalismo pudiera simplemente competir con el socialismo tras la segunda guerra mundial, 50 años después de haber alcanzado supuestamente su cenit, $y$ tras 30 de construcción socialista en la Unión Soviética, era ya poco creíble. Después de 1989, seguramente, ya no es necesario argumentar que las sociedades de tipo soviético no eran socialistas (no mostraban mayor capacidad de desarrollo de las fuerzas productivas), ni que el programa marxista-leninista parece ofrecer pocas posibilidades teóricas inmediatas" (1993, p. 12).

Por lo que hace a este esfuerzo de investigación, debemos finalmente decir que nos ha resultado no solo novedoso, sino profundamente estimulante, conmovedor $y$ a nuestro juicio constituye una contribución al análisis de la experiencia de la izquierda en Costa Rica que revela que aún queda mucha reflexión por delante.

18 de octubre del 2006

\section{BIBLIOGRAFÍA}

Dobles Oropeza, Ignacio y Leandro Zúñiga, Vilma: MILITANTES. La vivencia de lo político en la segunda ola del marxismo en Costa Rica. San José. CR. Editorial de la Universidad de Costa Rica. 2005.

Paramio, Ludolfo: "El materialismo histórico como programa de investigación". Publicado en E. Lamo de Espinoza y J.E. Rodríguez Ibáñez, compiladores, Madrid. Centro de Investigaciones Sociológicas. 1993. 